\title{
A INFLUÊNCIA DO BANCO MUNDIAL NO EMPRESARIAMENTO DA EDUCAÇÃO: CONSEQUÊNCIAS DA PARCERIA ENTRE O PÚBLICO-PRIVADO
}

\author{
Erika Ramos Januario, Jani Alves da Silva Moreira \\ Universidade Estadual de Maringá - UEM, Maringá, PR. E-mail:eriknha_ramos_@hotmail.com \\ e-mail:jasmoreira@uem.br
}

\section{RESUMO}

O objetivo deste estudo é analisar a influência das reformas educacionais orientadas pelo Banco Mundial (BM) na educação, após a década de 1990, a fim de apresentar as consequências da parceria entre o público-privado no ensino básico e superior. A pesquisa é qualitativa, de caráter bibliográfico e o método utilizado foi o Materialismo histórico, na medida em que este possibilita a análise da categoria totalidade, evidenciando as contradições existentes na sociedade capitalista. Os resultados foram de que a relação público-privado tornou o campo educacional um mercado atrativo para grupos empresariais, submetendo-a lógica mercantil. Conclui-se que a parceria possibilita o acesso e permanência das empresas em todos os setores do campo educacional, principalmente na atuação e formulação de políticas educacionais.

Palavras-chave: Banco Mundial; Reformas educacionais; Público-privado; Parcerias;Políticas educacionais.

\section{THE INFLUENCE OF THE WORLD BANK IN EDUCATION ENTREPRENEURSHIP: CONSEQUENCES OF PUBLIC-PRIVATE PARTNERSHIPS}

\begin{abstract}
The purpose of this study is to analyze the influence of World Bank (WB) -based education reforms on education after the 1990s to present the consequences of public-private partnership in primary and higher education. The research is qualitative, of a bibliographical character and the method used was historical Materialism, insofar as this allows the analysis of the category totality, evidencing the existing contradictions in capitalist society. The results were that the public and private relationship made the educational field an attractive market for business groups, subjecting it to commercial logic. It is concluded that the partnership allows the access and permanence of the companies in all sectors of the educational field, mainly in the actuation and formulation of educational policies.
\end{abstract}

Keywords: World Bank; Educational reforms; Public-private; Partnerships; Educational policies. 


\section{INTRODUÇÃO}

A pesquisa em questão apresenta uma análise sobre a influência que o Banco Mundial (BM) exerce na educação dos países periféricos, objetivando compreender quais foram as consequências dessa atuação na educação brasileira após 1990. Entende-se que os organismos e organizações internacionais tiveram papel fundamental no processo de financiamento de políticas para educação nos últimos anos. Principalmente o Banco Mundial (BM), que obteve como ponto fulcral ser o financiador, formulador, ator e produtor de ideias sobre "[...] o que fazer, como fazer, quem deve fazer e para quem em matéria de desenvolvimento capitalista" (PEREIRA, 2009, p.1) principalmente no que tangea educação dos países periféricos.

Todavia, o interesse pela educação nem sempre fez parte da agenda de interesses do Banco Mundial, pois até metade dos anos de 1970, os financiamentos "[...] privilegiavam os projetos de infraestrutura física, comunicação, transporte e energia, como medidas de base para o crescimento econômico" (FONSECA, 2001, p. 169). Pois a tese era de que ao criar políticas de desenvolvimento industrial e infraestrutural, tornar ia-se possível a inserção dos países periféricos no sistema comercial internacional, resultando consequentemente ascensão econômica e redução da pobreza dos mesmos (SILVA; AZZI; BOCK, 2005).

Com a entrada dos anos de 1980, os países periféricos que recebiam empréstimos do Banco Mundial, tiveram suas economias endividadas, devido à superprodução das suas mercadorias e o baixo fluxo de movimento dessas. Além do mais nesse período, a tese central de que a pobreza desapareceria com o crescimento econômico não se efetivou, devido ao fato que a mendicância não apenas persistiu, como também aprofundou a desigualdade entre os países ricos e pobres, obrigando o Banco a ampliar o leque de investimento nos setores, incluindo os setores sociais e de agricultura, indo, portanto, adiante de projetos de infraestrutura e industriais já existentes (SILVA; AZZI; BOCK, 2005).

A partir de 1990 o enfoque principal do Banco Mundial torna-se em financiar, orientar e assessorar as políticas educacionais dos países periféricos, obtendo a atenção prioritária na reforma educacional, para que assim, se obtenha uma maior eficiência, qualidade e equidade nos sistemas escolares. No Brasil, essa reforma ganha destaque no ensino básico e superior, com vistas para a privatização e mercantilização da educação, como poderá ser verificado na discussão que segue essa pesquisa.

Com base nessas considerações, acredita-se na importância de estudar sobre a influência do Banco Mundial nas reformas educacionais dos países periféricos, pois tais análises permitem entender a articulação presente sobre o interesse da classe dominante em tornar a educação um vasto mercado empreendedor, por meio da venda de assessoramento pedagógicos e de gestão escolar, comercialização de diplomas, privatização do ensino superior, além de criar diferentes estratégias, que responda exclusivamente formar trabalhadores para a demanda do mercado.

O objetivo desta pesquisa foi analisar a influência das reformas educacionais orientadas pelo Banco Mundial (BM) na educação, após adécada de 1990, a fim de apresentar as consequências da parceria entre o público-privado no ensino básico e superior.

\section{METODOLOGIA}

A presente pesquisa será qualitativa e o referencial teórico utilizado é o Materialismo histórico, pois compreende-se que não é possível aprender o significado de políticas educacionais em determinado contexto, sem a apreensão da lógica global de um determinado sistema de produção (MASSON, 2012). Assim, não é possível analisar as prováveis consequências das reformas educacionais, apresentadas nesta pesquisa, sem compreender que estas fazem parte de uma totalidade social, sendo importante o estudo da sua gênese, movimento e contradições.

Neste sentido, inicialmente a pesquisa concentrar-se-á nos pressupostos históricos da criação do Banco Mundial e sua influência na reforma educacional do países periféricos, para 
posteriormente analisar-se-á as consequências da relação público e privado na educação brasileira no ensino básico e superior.

\section{RESULTADOS}

A partir dos anos de 1990 o Banco Mundial orienta reformas para os países periféricos em todos os setores, principalmente no campo social. Estas obtinham como característica o aprofundamento das políticas de abertura comercial, desregulamentação e privatização, visando que, assim, a administração pública dos países periféricos se tornassem eficientes, com controle dos resultados e descentralizadas, se assemelhando a empresas privadas e tornado os cidadãos em " [...] "cliente privilegiado" dos serviços prestados pelo Estado" (BRASIL, 1995, p. 7).

Destarte, na conjuntura de reformas, o campo educacional adquire destaque e passa a ser proclamado como instrumento de redução da pobreza e fator importante para formação de capital humano, tornando-se requisito necessário no novo padrão de acumulação do capital (SEGUNDO; JIMENEZ, 2015).

No que tange a educação, o marco das reformas inicia-se a partir da Conferência Mundial sobre Educação para Todos (EPT), realizada em Jomtien, Tailândia, em 1990, convocada por agências internacionais como Nações Unidas para a Educação (UNESCO), Fundo das nações Unidas para a Infância (UNICEF), Programa das Nações Unidas para o Desenvolvimento (PNUD) e Banco Mundial. Esta conferência e teve como meta principal impulsionar reformas educacionais a serem implantadas nos países periféricos, inclusive no Brasil, influenciando o sistema educacional (FILHO, O.M. et al, 2016).

Cria-se nesta conferência o documento intitulado de Declaração Mundial de Educação para Todos, que tem como intuito criar esforços para oferecer a educação básica "[...] a todas as crianças, jovens e adultos" (UNESCO, 1998, p.4). Porém, conforme Pronko (2015, p. 96) "[...] educação para todos não significava a universalização da educação básica de maneira igualitária". Pois, logo no seu primeiro artigo, advoga-se que a "[..]amplitude das necessidades básicas de aprendizagem e a maneira de satisfazê-las variam segundo cada país e cada cultura" (UNESCO, 1998, p. 1).

Ou seja, vê-se a contradição existente nos próprios documentos, visto que ao analisar as entrelinhas percebe-se a lógica excludente do capitalismo, que fornece qual/que e como a educação será destinada conforme a importância do país dentro do sistema econômico vigente. Assim, os países mais ricos recebem uma educação voltada para formação intelectual e desenvolvimento dos conhecimentos científicos mais elaborados, já para os países mais pobres serão auferidos os conhecimentos mínimos destinados apenas para o mercado de trabalho e coesão social.

Para orientar as reformas educacionais e ser diretrizes políticas para as décadas subsequentes, o Banco Mundial elaborou o documento Prioridades y Estrategias para La Educacion (1995) ${ }^{1}$, o qual enfatiza a importância da educação básica (primária e secundária) para reduzir a pobreza, visando: aumentar a produtividade dos pobres; reduzir a fecundidade; melhor a saúde e aperfeiçoar os indivíduos para que estes possam participar plenamente na economia e na sociedade (BANCO MUNDIAL, 1995). O documento explicita que os programas que serão realizados pelo Banco incentivarão os governos a darem prioridades para a reforma educacional, visando buscar a equidade, especialmente no que tange a educação das meninas de países pobres, melhorar a qualidade dos resultados da aprendizagem, além de buscar a eficiência da gestão escolar por meio de parcerias com setores sociais e privados (BANCO MUNDIAL, 1995).

Para o ensino superior, o documento apresenta que é necessário fazer uma reforma que acate as seguintes recomendações: diferenciação; diversificação; redução do gasto público por aluno; eficiência e qualidade. Percebe-se que os discursos e orientações que fazem parte das

${ }^{1}$ Traduzido para língua portugueses se refere a “Prioridades e Estratégias para a Educação". 
orientações do Banco Mundial, definem a eficiência, qualidade e equidade, como palavras chaves para a reforma do ensino nos países periféricos, em que estas serão baseadas em amplos consensos nacionais e compromissos financeiros estáveis com o seu desenvolvimento.

Dessa maneira, as reformas nos países periféricos seguiram as instruções do Banco Mundial, e foram realizadas por meio de pacto entre os diferentes setores da sociedade, nomeadamente com os setores empresariais e das fundações privadas, resultando em um mecanismo de aproximação entre o setor público e o privado na área da educação ( KRAWCZYK, 2002). Assim o Estado passou a desempenhar o mínimo possível do seu papel na educação, respondendo à lógica neoliberal, e abriu as portas da escola para que empresas privadas se tornassem fatores decisivos nas tomadas de decisões, no executamento e definições de estratégias políticas no campo educacional com poderá ser observado na discussão a seguir.

\section{DISCUSSÃO}

Neste viés de reformas educacionais, o discurso do Banco Mundial enfatizado é de um Estado descentralizado, que promova parcerias com os setores privados no sistema educacional e que possibilite as famílias o direito livre de escolha em relação ao tipo de escola desejada para seus filhos. Assim, o Estado só participará oferecendo uma verba pública para a educação (primária e secundária) direcionada as famílias mais necessitadas, por meio de "cupons" oferecidos, para que estas famílias obtenham a oportunidade de "comprar" no mercado os serviços educacionais que mais se adaptem com sua realidade (HOFLING, 2001).

O discurso neoliberal elucida que este modelo de sistema educacional além de possibilitar a competição entre as escolas criará o sentido de missão entre os pais e comunidade, sendo este o "[...] sentimento que tem os alunos e os professores de que a escola é deles. Em vez de serem designados para uma escola, para receber uma escola padronizada, os estudantes podem escolher o tipo de educação que preferem. (OSBORNE; GAEBLER, 1998, p. 8).

Porém, essa proposta de ensino tem como objetivo estimular a competição entre as escolas, permitindo que estas ofereçam diferentes "pacotes educacionais" satisfazendo a necessidade dos pais (KRAWCZYK, 2002), além de incentivar a privatização das escolas, ao entregar de bandeja para o mercado de trabalho e torna-las em mercadorias que poderão ser submetida e moldadas conforme a logica mercadológica.

Com base na influência e orientações do Banco Mundial de ampliar as parcerias entre o público e privado nas reformas educacionais, estabeleceu-se também no ensino básico brasileiro a formação de mercados educativos, coma venda de materiais pedagógicos e pacotes educacionais que incluem "[...] aluguel de marca, pelo mecanismo de franquias, avaliações e formação em serviço do professor" (OLIVEIRA, 2009, p. 740). Esses materiais e pacotes pedagógicos são chamadas de sistemas privados de ensinos (SPE) que são vendidos aos municípios por grande redes de empresas privadas, sendo as principais: Grupo Objetivo, Positivo, Pearson, Abril educação e Grupo Santillana(ADRIÃO et al., 2019).

Estas marcas dominam o mercado educacional, principalmente na cidade de São Paulo, prestando a venda dos seguintes produtos e serviços que eram,

$\begin{array}{lcccccr}\text { integrada } & \text { por } & \text { atividades } & \text { tradicionalmente } & \text { desenvolvidas } & \text { pelas } \\ \text { equipes } & \text { pedagógicas dos órgãos da administração } & \text { pública e } & \text { das } \\ \text { escolas: } & \text { formação } & \text { continuada } & \text { de } & \text { educadores, } & \text { acompanhamento } \\ \text { e supervisão das atividades docentes; investimento na produção e distribuição de } \\ \text { materiais } & \text { didáticos } & \text { aos } & \text { alunos } & \text { e } & \text { processos }\end{array}$

de avaliação externa e interna. (ADRIÃO et al., 2009, p. 806)

Nesta ótica, constata-se que grupos de empresas tem objetivado criar novas formas de lucros que vão além da oferta de ensino em escolas privadas. Nota-se que neste contexto, pós neoliberal, a mercantilização dos assessoramentos pedagógicos e da gestão escolar tonar-se 
crescente, distanciando-se cada vez mais da realidade da própria escola e ampliando a privatização da educação com um mercado competitivo.

No ensino superior, percebe-se a expansão das instituições de ensino privado em que estas possuem "[...] quase $3 / 4$ (três quartos) das matrículas totais na graduação, demonstrando a consolidação de um verdadeiro mercado de educação superior no Brasil" (AZEVEDO, 2015, p. 89). Nota-se a saliente privatização dessa modalidade de ensino, onde a maioria dos estudantes são consumidores de educação e pagam diretamente anuidade escolares, ou são financiados por intermédio de bolsas pelo Programa Universidade para Todos (PROUNI) ou pelo Fundo de Financiamento Estudantil (FIES) (AZEVEDO, 2015).

Dessa maneira, percebe-se que a educação torna-se um mercado atrativo para as empresas privadas, que passam a lucrar, de um lado, com os estudantes que fazem financiamento e compram o serviço educacional e do outro, com os municípios que utilizam recursos públicos para comprar assessoramento pedagógico e de gestão.

\section{CONCLUSÃO}

Com base no esboço apresentando, nota-se que Banco Mundial a partir de 1990, objetivou responder aos problemas inerentes ao capitalismo (econômicos e sociais) buscando soluções no campo educacional. Nesta conjuntura de busca por soluções, foram criadas reformas em diversos setores administrativos públicos, principalmente na educação, fomentando a parceria de empresas no sistema educacional e visando que estas tornassem a educação mais eficiente, flexível e formadora de trabalhadores qualificados para o mercado de trabalho.

Como consequência dessa parceria, percebe-se que a educação tornou-se um mercado atrativo de negócios, ficando submetida à lógica mercantil de determinados grupos empresariais. Assim, o Estado continuou a ser responsável pelo acesso e permanência dos alunos nas escolas públicas do ensino básico, porém o assessoramento pedagógico e da gestão escolar passou a ser de responsabilidade de determinadas empresas, com o argumento de que estas introduziriam a qualidade para o sistema educacional. Além do mais, no que tange ao ensino superior, observouse que esta modalidade não se diferenciou do ensino básico ao ser cada vez mais dominada pelas empresas privadas, principalmente no exorbitante comércio do lucro, ou seja do financiamento e venda de diplomas. Por fim, conclui-se que a parceria público-privado fortalece o setor empresarial, fazendo com que estes tenham o acesso permanente em todos setores do campo educacional, principalmente na atuação e formulação de políticas educacionais.

\section{REFERÊNCIAS}

ADRIAO, T. et al. Uma modalidade peculiar de privatização da educação pública: a aquisição de "sistemas de ensino" por municípios paulistas. Educ. Soc. [online]. v. 30, n. 108, p. 799-818, 2009. https://doi.org/10.1590/S0101-73302009000300009

AZEVEDO, M. L. N. Transnacionalizaçãoe mercadorização da educação superior: examinando alguns efeitos colaterais do capitalismo acadêmico (sem riscos) no Brasil - a expansão privadomercantil. Revista Internacional de Educação Superior [RIESup], Campinas, v. 1, n. 1, p. 86-102, 2015a.

BANCO MUNDIAL. Prioridades y estrategias para la educacion: Examen Del Banco Mundial. Washington, 1995.

BRASIL. Plano Diretor da Reforma do Aparelho do Estado. Brasília, 1995. 
FILHO, O.M. et al. O Empresariamento da educação: uma análise da reforma educacional da década de 1990. In: RABELO, J. (Org.) O movimento de educação para todos e a crítica marxista. Fortaleza: Imprensa Universitária, 2015. P.67-100.

FONSECA, M. O Banco Mundial e a educação: Reflexões sobre o caso Brasileiro. In:GENTILI, Pablo. Pedagogia da exclusão: crítica ao neoliberalismo em educação. Petrópolis, Rio de Janeiro; Vozes, 2001.

HOFLING, E. M. Estado e políticas (públicas) sociais. Cad. CEDES [online]. 2001, vol.21, n.55, pp.3041. ISSN 0101-3262.

KRAWCZYK, N. A sustentabilidade da reforma educacional em questão: a posição dos organismos internacionais. Rev. Bras. Educ. [online]. 2002, n.19, pp.43-62. ISSN 1413-2478.

MASSON, Gisele. As contribuições do método materialista histórico e dialético para a pesquisa sobre políticas educacionais. In: IX ANPED SUL, SEMINÁRIO DE PESQUISA EM EDUCAÇÃO DA REAGIÃO SUL, 2012.

OLIVEIRA, R. P. de. A Transformação da Educação em Mercadoria no Brasil. Educação e Sociedade. Campinas, v. 30, n. 108, p. 739-760, out. 2009.

OSBORNE, D.; GAEBLER, T. Reinventando o governo: como o espírito empreendedor está transformando o setor público. 6.ed. Brasília, D.F.: MH Comunicação, 1998.

PEREIRA, P. A. P. Discussões conceituais sobre política social como política pública e direito de cidadania. In: BEHRING, Elaine Rossetti; BOSCHETTI, Ivanete; SANTOS, Silvana Mara de Morais dos; MIOTO, Regina Célia Tamaso. (Orgs.) Política Social no capitalismo: tendências contemporâneas. 2. ed., São Paulo: Cortez, 2009.

SEGUNDO, M. D. M.; JIMENEZ, S. O papel do Banco Mundial na Reestruturação do capital: estratégias e inserção na política educacional brasileira. In: RABELO, J. (Org.) O movimento de educação para todos e a crítica marxista. Fortaleza: Imprensa Universitária, 2015. p. 46-57.

SILVA, C. C.; AZZI, D.; BOCK, R. (Org.) Banco Mundial em Foco: um ensaio sobre sua atuação na educação brasileira e na dos países que integram a Iniciativa Via Rápida na América Latina. São Paulo: Ação Educativa, 2005.

UNESCO. Declaração Mundial sobre Educação para Todos: satisfação das necessidades básicas de aprendizagem. Jomtien, 1998. 